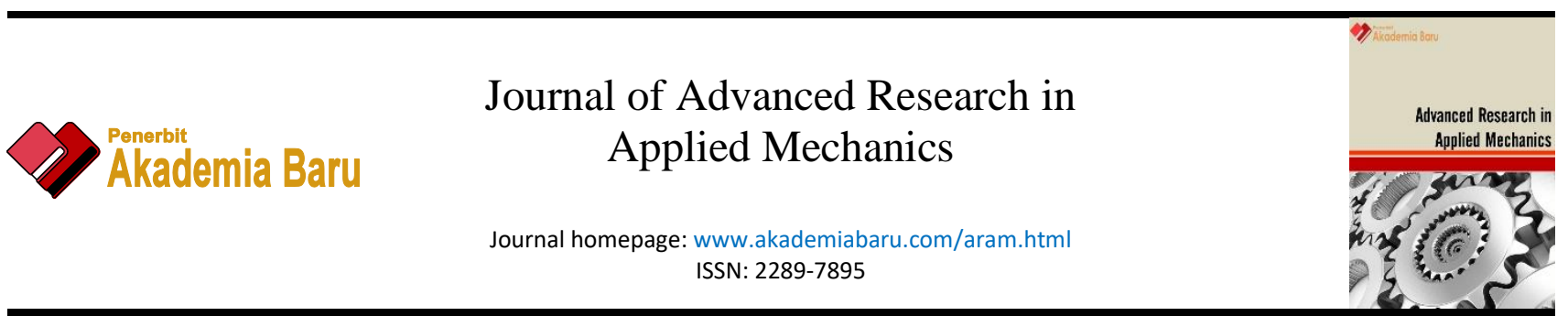

\title{
Heterolithic Thin Bedded Reservoirs Volumetric Estimation, Quantification and High-Resolution 3D Modelling
}

\author{
Stanley Jaul Kampit ${ }^{1,}{ }^{*}$, Samira Albati Kamaruddin², Tuan Zaid Tuan Muda ${ }^{1}$, Zulkarnain Abdullah \\ Anas $^{1}$, Mohd Nor Hisham Mohd Azam ${ }^{3}$
}

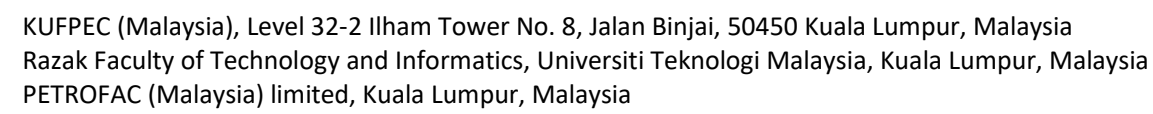

\section{ABSTRACT}

The heterolithic thin-bedded sand and shale are very commonly associated reservoirs column in shallow water clastic depositional environment in Malaysia Basin. The complexity in reservoirs characterization of heterolithic thin-bedded sand often leads to underestimating the potential contribution of these types of the reservoir for development and exploration targets. The naturally laminated of heterolithic thin-bedded sand make it more difficult in building the realistic 3D geological model and has an impact on volumetric calculation and reserve estimation. This study is applied in the development phase by introducing Log resolution enhancement methods in laminated thin-bedded sand characterization to quantify the reservoir potential with high-resolution 3D modelling methods. The quantification of sand and shale in thin bedded analysis using core data and image logs, then transform into lithofacies classification from sand and shale volume cut-off. The distribution and computation of lithofacies and reservoir properties build into a 3D model is obtained from a geological depositional environment analog at field-scale of a conventional setting. The results indicated high-resolution 3D geological modelling successfully preserved the characterization of thin-bedded sand and shale; and revealed an excellent correlation with the image log. The presence of inter-bedded sand and shale of reservoir column in the 3D geological model provides the quantification of thin-bedded sand contribution and potential realistic volumetric estimation for the entire reservoir interval. The thin-bedded reservoir characterization and high-resolution 3D modelling technique successfully address the existent of heterolithic reservoir facies previously simplified.

\section{Keywords:}

Heterolithic Reservoirs, thin-bedded,

Volumetric, 3D modelling, Low Resistivity

Low Contrast, inter-bedded

Copyright $@ 2020$ PENERBIT AKADEMIA BARU - All rights reserved

\section{Introduction}

The heterolithic reservoirs contribution is important to unlock the field potential for development optimization. Most of the production fields in Malaysia basin and around the globe are from conventional reservoir associated with heterolithic thin bedded (HTB) [1-6]. Heterolithic Reservoir description depending on scale of thin bedded, heterogeneous, or laminated pay, which refer to the formation with two or more sand members that non-communicating, each probably with distinct relative and specific permeability characteristics as explain by Henderson et al., [7], Kantaatmadja et

\footnotetext{
* Corresponding author.

E-mail address: stanley.kampit@gmail.com
}

https://doi.org/10.37934/aram.65.1.110 
al., [9], Nayagawa et al., [12], Stromberg et al., [15]. The HTB is refer to permeable beds interbedded with impermeable shales bedded with millimeter $(\mathrm{mm})$ to centimeter $(\mathrm{cm})$ thickness, which is below standard log resolution and commonly associated with conventional reservoirs. The reservoir characterization of HTB net pay requires high resolution of data such as cores, image logs, MNR and other special logs together with conventional logs. The problem in quantifying and evaluating the net pay in HTB reservoirs still exists till today. The real challenge is to build the realistic 3D geological modelling for HTB and quantifying the impact on volumetric calculation, reserves estimation and geological simulation within conventional reservoirs.

The quantification of HTB net pay from thin bedded analysis (TBA) technique using logs resolution enhancement (LRE) method are requires high resolution of data such as cores, image logs, Nuclear magnetic resonance (NMR) and other special logs together with conventional logs. According to Moore [11], Darling and Sneider cited several causes that impact the logging tool to produce low resistivity reading then normal inside the pay zone beside bed thickness, such as grain size, mineralogy, structural dip, clay distribution and water salinity. However, the thin beds highly conductive shale interbedded with thin sand which are below vertical resolution of the logging tool is the most common cause that create the Low Resistivity Low Contrast (LRLC) inside HTB zone.

The discussion on the potential exploration and production of oil and gas from laminated thin bedded sand-shale in HTB net pay quantification, which significant impact to the total hydrocarbon initial in place (HIIP) volume. The other objective is to identify the common procedure towards 3D modelling process, to reduce uncertainties and to increase the accuracy in HIIP volume estimation for reservoir simulation and history match.

\section{Methodology}

This study focused at HTB net pay quantification, the potential in volumetric estimation and contribution into conventional clastic reservoirs development through 3D modelling and simulation. The similar scenario for HTB also may exist in carbonate rock and unconventional reservoirs. The Thin Bedded Analysis (TBA) with logs resolution enhancement (LRE) technique are used for petrophysical quantification of HTB net pay.

The LRE results with high resolution of properties logs output integrated into high-resolution 3D geomodelling methods to quantify and estimate the Hydrocarbon (HC) volume and the reservoir simulation to testing the impact of HTB in conventional system. The review from literature and historical analogues used to determine the HTB percentages within conventional pay associated with geological depositional environment (GDE). The distribution and computation of depofacies, lithofacies, reservoir properties and geobodies parameter in 3D geological model are obtained from literature review and GDE analogues at field-scale of a conventional setting, based on industry published data reviewed.

The flowchart (Figure 1) illustrates the 3D static model workflow employed in this study. In summary, the main process includes data preparation, structural modelling (faults and horizons), geological 3D gridding, log property up-scaling ("blocking"), facies modelling, petrophysical modelling and volumetric analysis. 


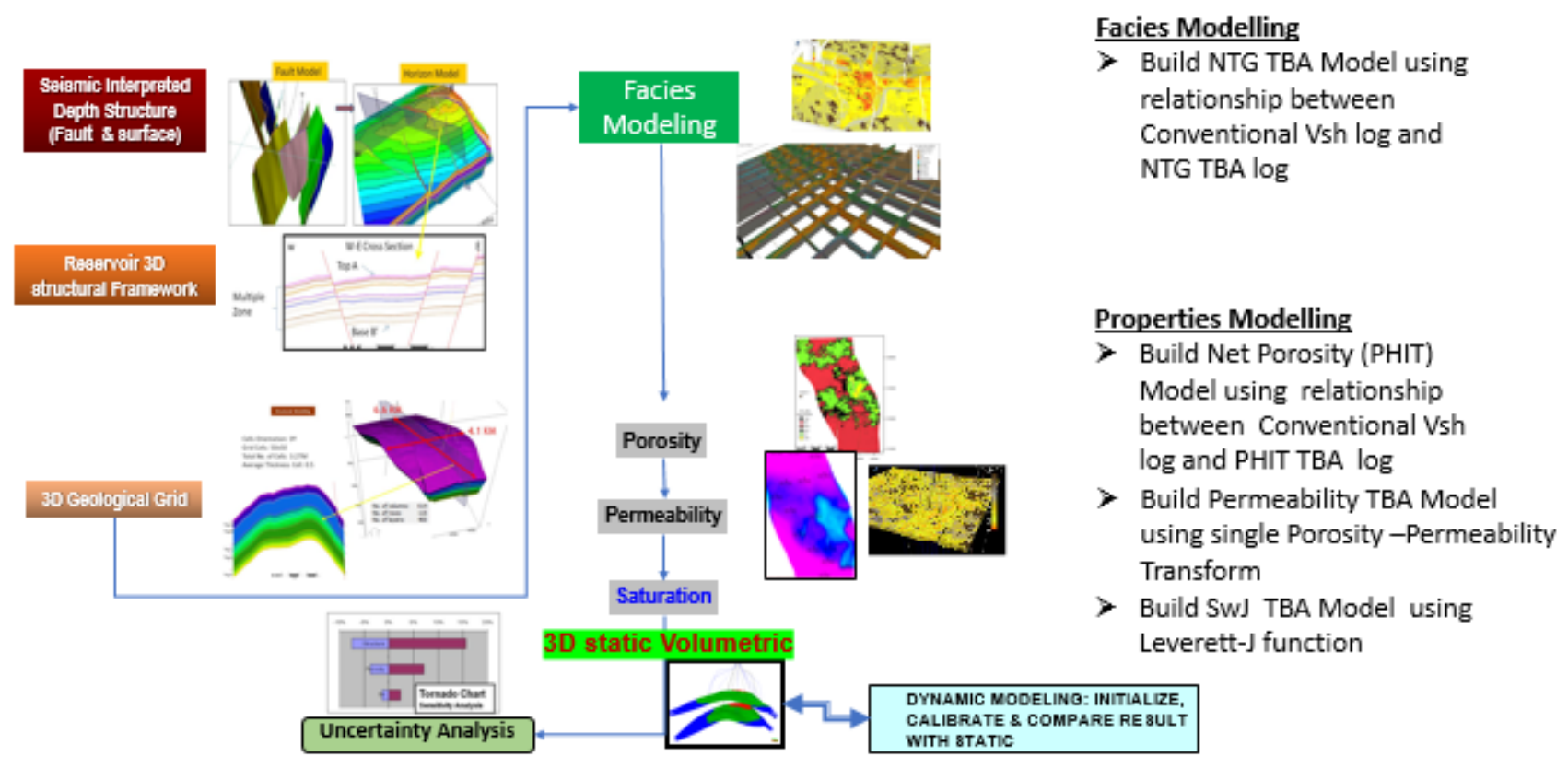

Fig. 1. The 3D static model workflow used and employed to build high resolution model incorporating the TBA for heterolithic reservoirs

\section{Results}

The results indicated high-resolution 3D geological modelling successfully preserved the characterization of HTB sand and shale, revealed an excellent correlation with the image log correlated with TBA result. The presence of inter-bedded sand and shale of reservoir column in the 3D geological model provides the quantification of thin-bedded sand contribution and potential realistic volumetric estimation for the entire reservoir interval.

\subsection{Petrophysical Analysis}

The complexity in reservoir characterization from petrophysical analysis in respect of HTB net pay quantification requires signification details and high resolution of data. The TBA improves the total water saturation (SWT) and net sand property. The results between the conventional and the TBA are then compared (Figure 2). While improving the SWT of the net sand, the total pore column thickness is maintained, and additional gain in pore column thickness (PT) or pore volume (PV).

The result from LRE for net-to-gross (NTG), Volume of Sand (Vsand), Volume of Shale (VSH) and total porosity (PHIT) and permeability in high resolution log (HRL) sampling format ( 0.2 inch), similar resolution as the resistivity-based wellbore image log (Figure 3). The use of the upscaled instead of high-resolution logs as inputs into the modelling should not affect the calculation of the hydrocarbon in place as the hydrocarbon column thickness between the TBA HRL and the upscaled $0.15 \mathrm{~m}$ results are quite comparable. 


\begin{tabular}{lcccccc}
\multirow{2}{*}{ Well } & \multicolumn{5}{c}{ PT } \\
\cline { 2 - 7 } & SR (6 in) & $H R(0.2 \mathrm{in})$ & Net Sd $(6 \mathrm{in})$ & $S R(6 \mathrm{in})$ & $H R(0.2 \mathrm{in})$ & Net Sd $(6 \mathrm{in})$ \\
\hline Well A & 6.76 & 7 & 5.54 & 3.24 & 3.71 & 3.6 \\
\hline Well B & 2.49 & 2.61 & 1.65 & 0.45 & 0.77 & 0.75 \\
\hline Well C & 7.4 & 7.77 & 5.61 & 3.66 & 3.71 & 3.72 \\
\hline Well D & 3.67 & 3.67 & 2.46 & 1.26 & 1.12 & 1.12 \\
\hline Well F & 5.63 & 5.86 & 4.62 & 2.76 & 2.1 & 2.1 \\
\hline Well G & 6.11 & 6.27 & 4.59 & 2.24 & 2.33 & 2.19 \\
\hline Well H & 4.7 & 4.8 & 2.89 & 1.6 & 2.12 & 2.06 \\
\hline Well I & 8.13 & 8.24 & 5.65 & 2.77 & 2.29 & 2.3 \\
\hline Well J & 3.73 & 3.81 & 3.00 & 1.21 & 1.42 & 1.41 \\
\hline Well K & 3.73 & 3.73 & 3.05 & 1.91 & 2.16 & 2.15 \\
\hline
\end{tabular}

Fig. 2. The compare the TBA results with the one from the conventional analysis in term of pore (PT=PHIT*Thickness_TVD) and hydrocarbon column thickness (HCPT=PHIT* (1-SWT) *Thickness_TVD)

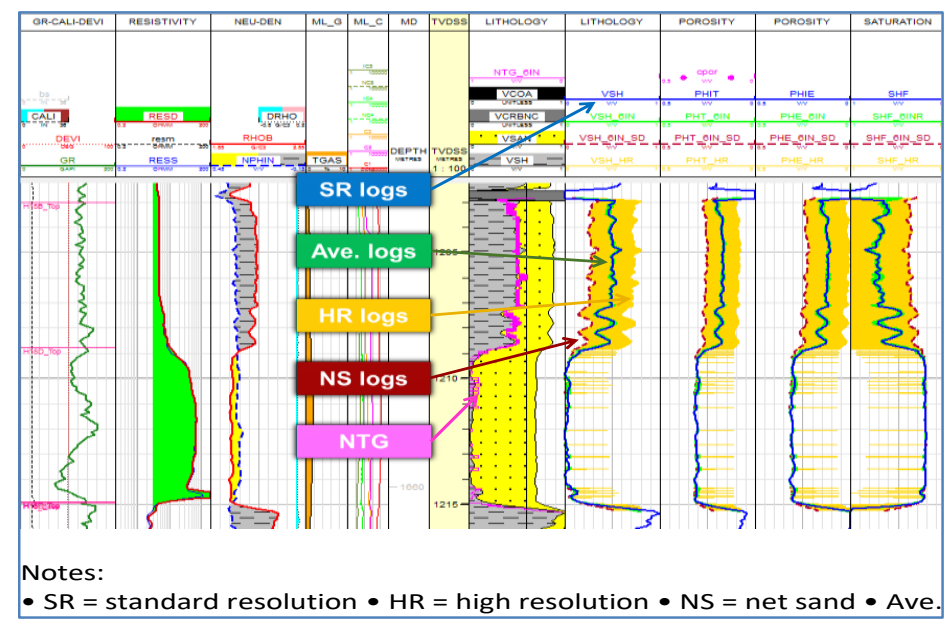

Fig. 3. Log composite (right) show the comparison of Standard Resolution (SR), High Resolution (HR) and Net Sand (NS) logs

\subsection{D Static Model}

The high-resolution 3D geological model (3D Static model) used to estimates the HC volume and provide the simulation model for production history matching. To preserve the thin bed resolution and maintain the well statistic, the cell thickness geological grid was refined to a smaller value. The cell thickness is $0.15 \mathrm{~m}$ which is more or less equivalent to the thin bed resolution (Figure 4), however, the increase in total grid cells will compromise the efficient simulation time. 


\section{Refined Reservoir 3D Cell thickness $=0.15 \mathrm{~m}$}
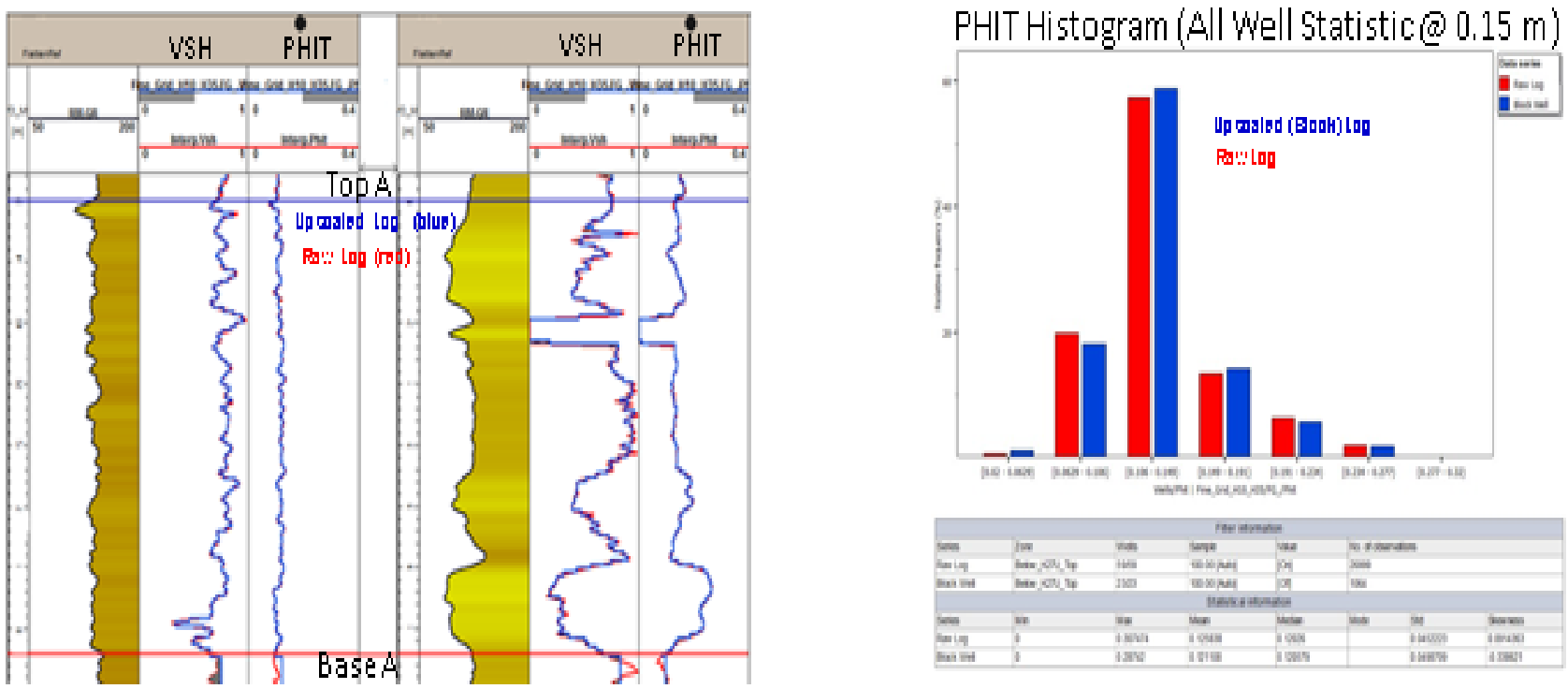

Fig. 4. Comparison of high-resolution logs (Raw) and upscaled (Block) in $3 \mathrm{D}$ model (left) and PHIT histogram between Raw and upscaled at $0.15 \mathrm{~m}$ vertical thickness (right) show at good match

The workflow applied for 3D property modelling with HR (TBA) and combination of standard resolution (SR) from conventional analysis is shown as below (Figure 5). The most important step in thin bed modelling workflow is to relate the thin bed parameter to the existing conventional model.

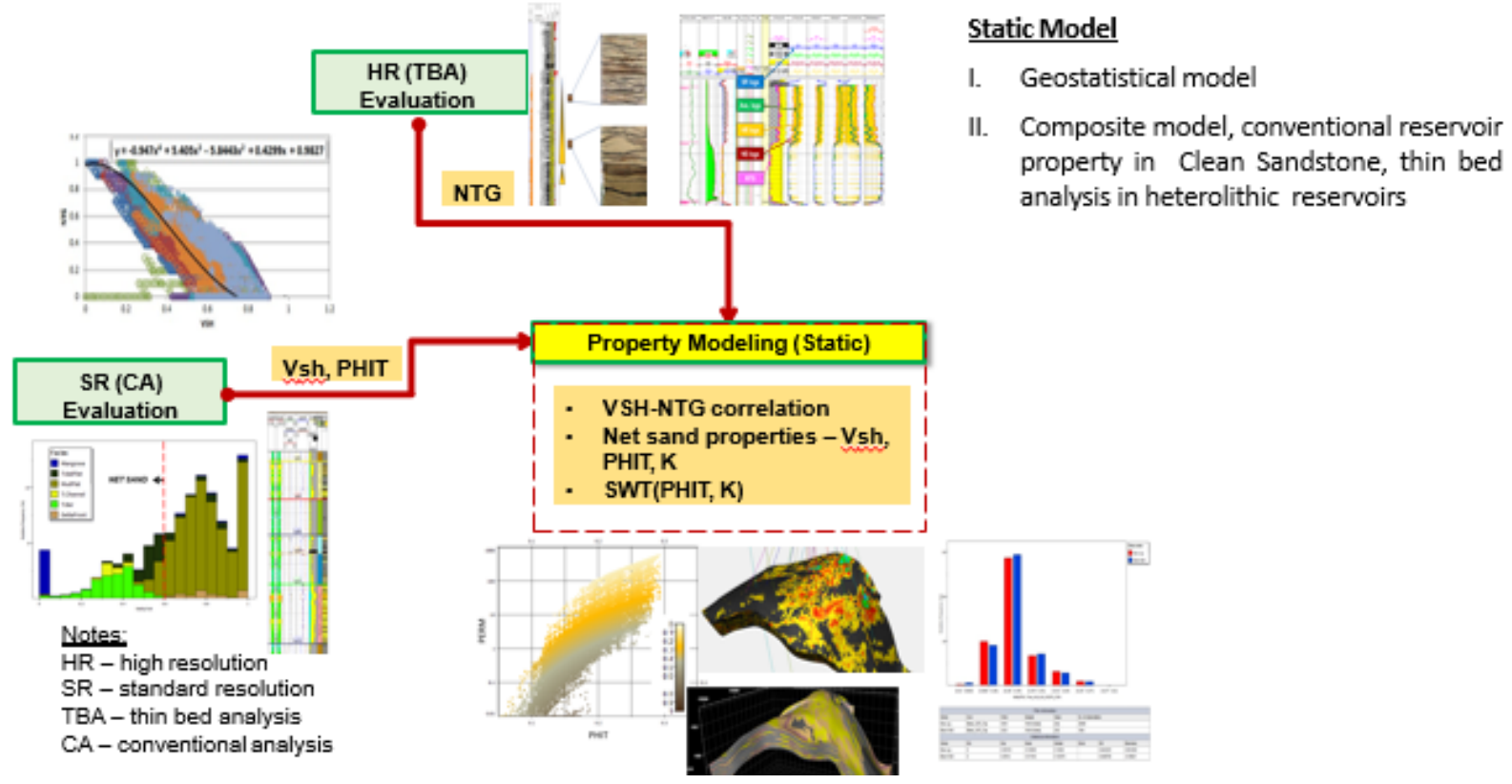

Fig. 5. The workflow applied for 3D property modelling with HR (TBA) and combination of standard resolution (SR) from conventional analysis 
There are four geological grids to be modelled which Net-To-Gross (NTG), Net Porosity (NP), Net Permeability (K), and Net Water Saturation (SWT). The NTG is more or less a function of an inverse VSH conventional (NTG = $1-\mathrm{VSH}$ ). The bin method is used to define the rock type or facies as the base case model and the net permeability $(K)$ was modelled using a porosity-permeability relationship shown (Figure-6).

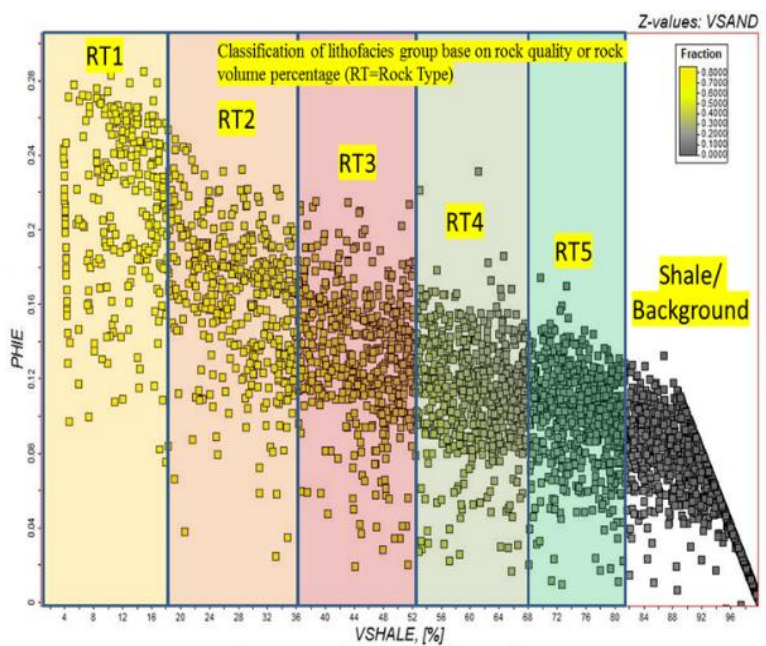

Poro-Vsh- Rock type classification

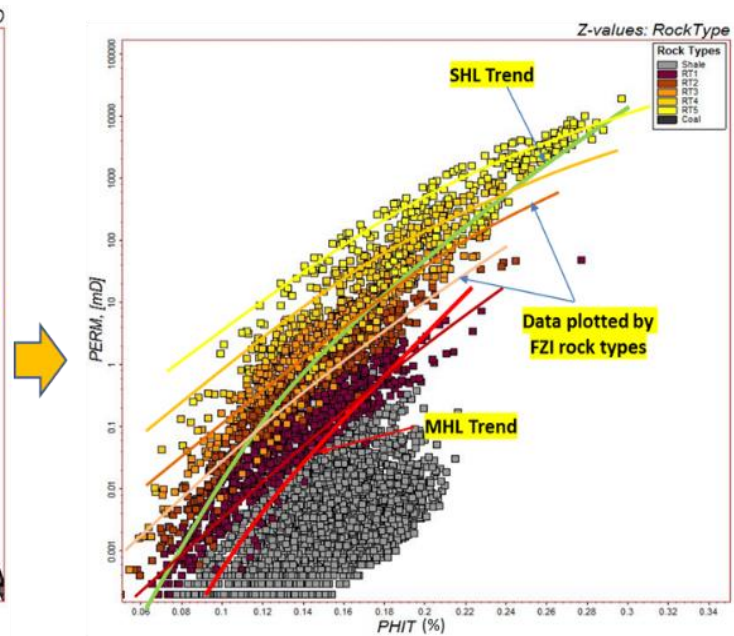

Poro-Perm relationship Function

Fig. 6. Using the bin method to classify the rock type from Poro-Vsh relationship (left) and the PoroPerm function derived from log relationship

The result of net permeability model calculated using this relationship shown improvement in connectivity and reservoir capacity significantly, compare with conventional method and eventually improves the history match (Figure-7).

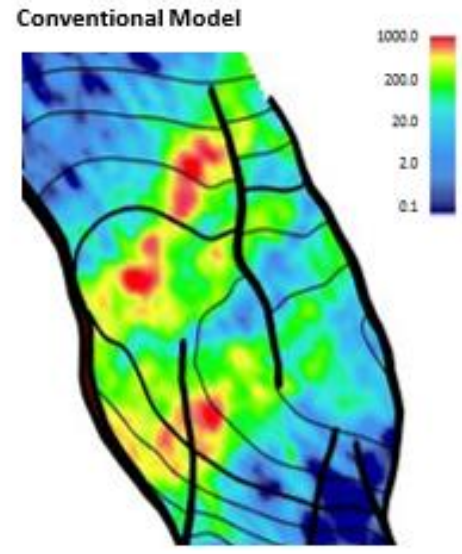

Conventional Model (Vsh<0.60)

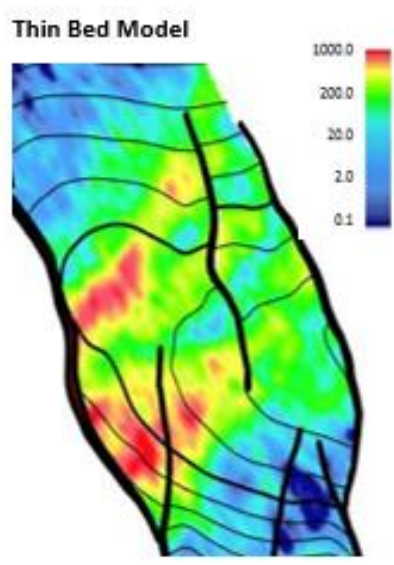

Thin Bed Model

- Improved Permeability in the Net Reservoir layer

- Better lateral connectivity

Fig. 7. Comparison map of horizontal permeability $(\mathrm{Kh})$ between the Conventional Model (left) and the improved Thin Bed Model (right) 
The final property model in the thin bed modelling workflow is the water saturation (Sw) where the same Leverett-J function is applied to the conventional model. Overall, the hydrocarbon pore volume (HCPV) has improved significantly in the net reservoir layer and introduces better lateral connectivity, in agreement with the dynamic behaviour (Figure-8).

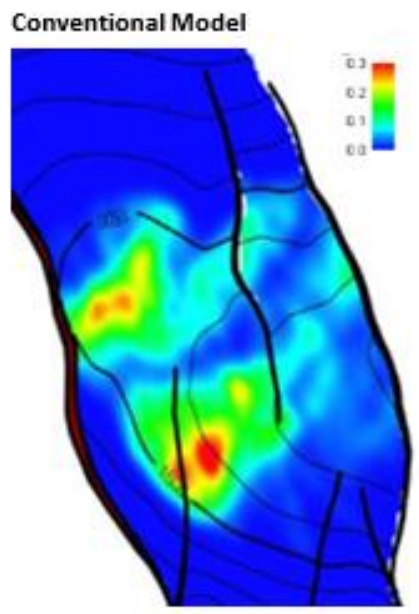

Net cut-off $=$ Vsh $<0.60(60 \%)$

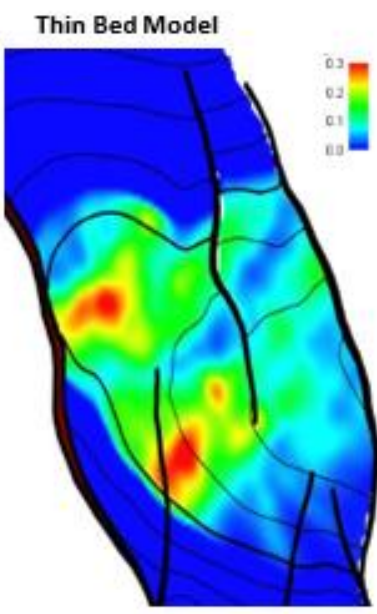

Thin Bed Model

- Improved HCPV (Net*PHIT*So) in the Net Reservoir layer

- Better lateral connectivity

Fig. 8. Comparison of HCPV map between the Conventional Model (left) and Thin Bed Model (right). The Thin Bed Model has improved HCPV in net reservoir layer and better lateral connectivity

\subsection{Dynamic Model Initialization and Validation}

The 3D Static and Dynamic model initialization and validation process workflow is shown in Figure 9. No upscaling is applied from high resolution 3D static $(0.15 \mathrm{~m}$ vertically) to Dynamic model.

The first version of Dynamic model run using conventional petrophysical interpretation for property modelling indicated that insufficient connected STOIIP and permeability-thickness (k-h) in all wells to match the historical data. However, result from high resolution model with TBA (Figure10) showed a good history match obtained without any significant application of local modifiers around the wells. This further confirmed the underestimation of reservoir properties in thinly bedded reservoirs. 

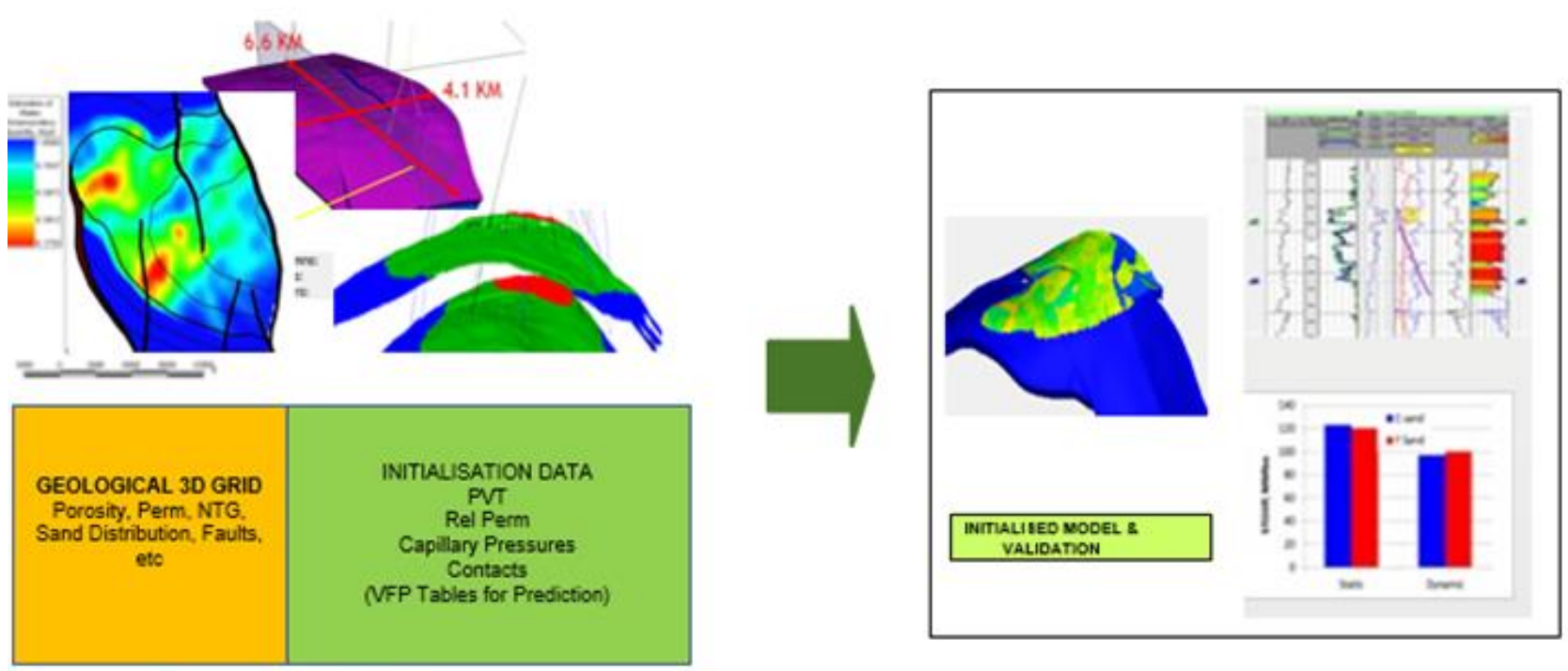

\section{FEEDBACK TO}

STATIC MODEL

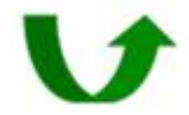

$>$ No upscaling from Static model

$>$ Model size: Total cells 3D static $=$ Dynamic model

Average grid cell size: $50 \mathrm{~m} \times 50 \mathrm{~m} \times 0.15 \mathrm{~m}$

Fig. 9. The 3D Static and Dynamic model initialization and validation process workflow

Production profile : Conventional with normal grid

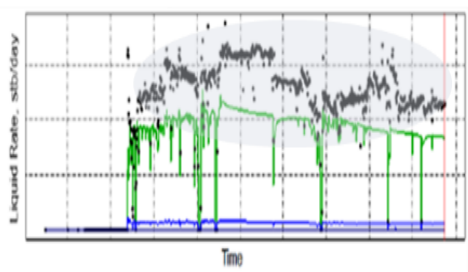

Production profile: Thin Bedded Analysis with High-resolution grid

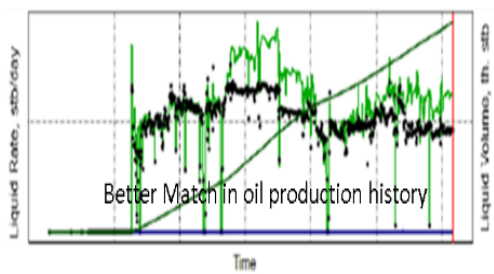

Fig. 10. Comparison of history match using conventional and Thin Bedded analysis with high resolution grid shown a better match

\subsection{Volumetric and Uncertainty Assessment}

The high-resolution 3D model with thin bedded petrophysical analysis provide more accurate estimation of total HIIP as the contribution from thin bedded reservoirs has provided more volume. The heterolithic reservoirs modelling with TBA using high resolution model has moved uncertainty analysis of Best case to the upside potential (Figure 11). 


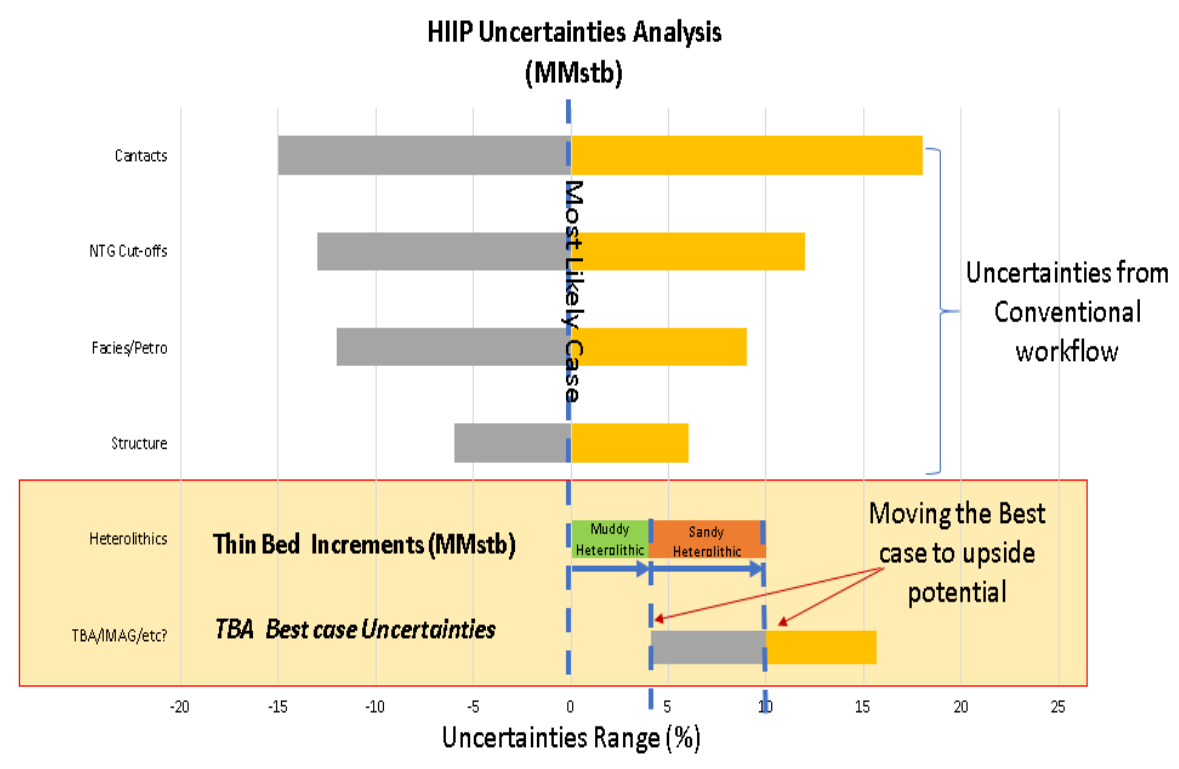

Fig. 11. The heterolithic reservoirs modelling with TBA using high resolution model has moved uncertainty analysis of Best case to upside potential

\section{Conclusions}

The results indicated high-resolution 3D geological modelling successfully preserved the characterization of HTB sand and shale, revealed an excellent correlation with the image log correlated with TBA result. The presence of inter-bedded sand and shale of reservoirs column in the 3D geological model provides the quantification of thin-bedded sand contribution and potential realistic volumetric estimation for the entire reservoir interval. The thin-bedded reservoir characterization and high-resolution 3D modelling technique successfully addresses the existent of heterolithic reservoir facies previously simplified. It is highly recommended in 3D modelling for heterolithic reservoirs in order to avoid underestimation of rock properties and better reflect the highly laminated nature of the reservoirs for volumetric evaluation.

\section{Acknowledgement}

Appreciation and thank you to Co-Authors, Supervisors and Universiti Teknologi Malaysia for support, facilitate and provide the platform to publish this journal.

\section{References}

[1] Baillie, Kathleen Anne, and Jennifer James-Romano. "Identifying and Quantifying Thin Bedded Pay (TBP)(Part B): The Use of Dynamic Data to Evaluate Productivity Potential in Gas Reservoirs." In Trinidad and Tobago Energy Resources Conference. Society of Petroleum Engineers, 2010. https://doi.org/10.2118/133535-MS

[2] Bastia, Ravi Narayan, Anil Kumar Tyagi, Kamlesh Saxena, Theodore Klimentos, Raphael Mark Altman, Steve Alderman, and Somesh Bahuguna. "Evaluation of low-resistivity-pay deepwater turbidites using constrained thinbed petrophysical analysis." In SPE Annual Technical Conference and Exhibition. Society of Petroleum Engineers, 2007. https://doi.org/10.2118/110752-MS

[3] Bridge, J. S., and S. D. Mackey. "A theoretical study of fluvial sandstone body dimensions." The geological modelling of hydrocarbon reservoirs and outcrop analogues (1992): 213-236. https://doi.org/10.1002/9781444303957.ch14

[4] Bruyelle, Jérémie, and Dominique R. Guérillot. "An accurate volumetric calculation method for estimating original hydrocarbons in place for oil and gas shales including adsorbed gas using high-resolution geological model." In IPTC 
2014: International Petroleum Technology Conference, vol. 2014, no. 1, pp. 1-12. European Association of Geoscientists \& Engineers, 2014. https://doi.org/10.2523/IPTC-17670-MS

[5] Bryant, I. D., and S. S. Flint. "Quantitative clastic reservoir geological modelling: problems and perspectives." The geological modelling of hydrocarbon reservoirs and outcrop analogues (1992): 1-20. https://doi.org/10.1002/9781444303957.ch1

[6] Chong, E. E., M. N. H. Azam, P. B. James, S. F. Rae, and S. Flew. "Application of Thin-Bed Analysis in Reservoir Modelling to Unlock Further Development Potential of Thinly-Bedded Marginal Reservoirs." In SPE/IATMI Asia Pacific Oil \& Gas Conference and Exhibition. Society of Petroleum Engineers, 2017. https://doi.org/10.2118/186425-MS

[7] Henderson, Katy, Hilary Jane Rose, and Rene Winter. "Identifying and quantifying thin bedded pay (Part A): log characteristics and reservoir quality." In Trinidad and Tobago Energy Resources Conference. Society of Petroleum Engineers, 2010. https://doi.org/10.2118/133534-MS

[8] Jackson, Matthew D., Shuji Yoshida, Ann H. Muggeridge, and Howard D. Johnson. "Three-dimensional reservoir characterization and flow simulation of heterolithic tidal sandstones." AAPG bulletin 89, no. 4 (2005): 507-528. https://doi.org/10.1306/11230404036

[9] Kantaatmadja, Budi P., Syamsina Bt Rashid, Achmad A. Nurhono, Rahim Masoudi, Tom Neville, Kim Taesoo, and Debnath Basu. "Thinly Bedded Reservoir Study, Application of Sand-Slit-Clay (SSC)-SHARP-Thomas Stieber Juhasz Models, in a Deep Water Field, Offshore Sabah, Malaysia." In SPE/IATMI Asia Pacific Oil \& Gas Conference and Exhibition. Society of Petroleum Engineers, 2015. https://doi.org/10.2118/176302-MS

[10] Kherroubi, Josselin, Carlos Maeso, Yinyu Wang, and Helena Gamero-Diaz. "Lamination Analysis from Electrical Borehole Images: A Quantitative Workflow." In SPWLA 57th Annual Logging Symposium. Society of Petrophysicists and Well-Log Analysts, 2016.

[11] Shelton, Glenmore, and W. A. Hill. "Productive low resistivity well logs of the offshore Gulf of Mexico: a summary." (1993): A1-A8.

[12] Nayagawa, Asmau, Kefe Amrasa, Olukayode Ayeni, Abdul-Wahab Sa'ad, and Olaseni Osho. "Production Optimization of Heterolithic Reservoirs through Completion Strategy and Reservoir Management: A Case Study of Cream Field." In SPE Nigeria Annual International Conference and Exhibition. Society of Petroleum Engineers, 2014. https://doi.org/10.2118/172493-MS

[13] Ni, Chai Shin, Steve Carney, Libny Leal, Dave Boardman, and Keith Shepstone. "Low resistivity low contrast pay in complex Miocene reservoirs of the Malaysia Thailand Joint Development Area (MTJDA)." (2008).

[14] Passey, Quinn R., Kenneth E. Dahlberg, Keith Sullivan, Hezhu Yin, Bob Brackett, Yuehui Xiao, and Angel G. GuzmanGarcia. Petrophysical evaluation of hydrocarbon pore-thickness in thinly bedded clastic reservoirs: AAPG Archie Series, no. 1. No. 1. Aapg, 2006. https://doi.org/10.1306/A11157

[15] Stromberg, Simon, Robbert Nieuwenhuijs, Conrad Blumhagen, John Edwards, Raghu Ramamoorthy, and Bernd Herold. "Reservoir Quality, Net-to-Gross, and Fluid Identification in Laminated Reservoirs from a new generation of NMR logging tools. Examples from the Gharif Formation, Southern Oman." In SPWLA Middle East Regional Symposium. Society of Petrophysicists and Well-Log Analysts, 2007.

[16] Amelio Tolioe, William, B. Mat Ismail, M. Shah, Astia Angelia Hutajulu, Gamal Ragab Gaafar, and Faizah Bt Musa. "Low Resistivity Pay Evaluation, Case Study: Thin Bed Sand-Shale Lamination Reservoirs, Peninsula, Malay Basin." In International Petroleum Technology Conference. International Petroleum Technology Conference, 2016. https://doi.org/10.2523/IPTC-18724-MS 